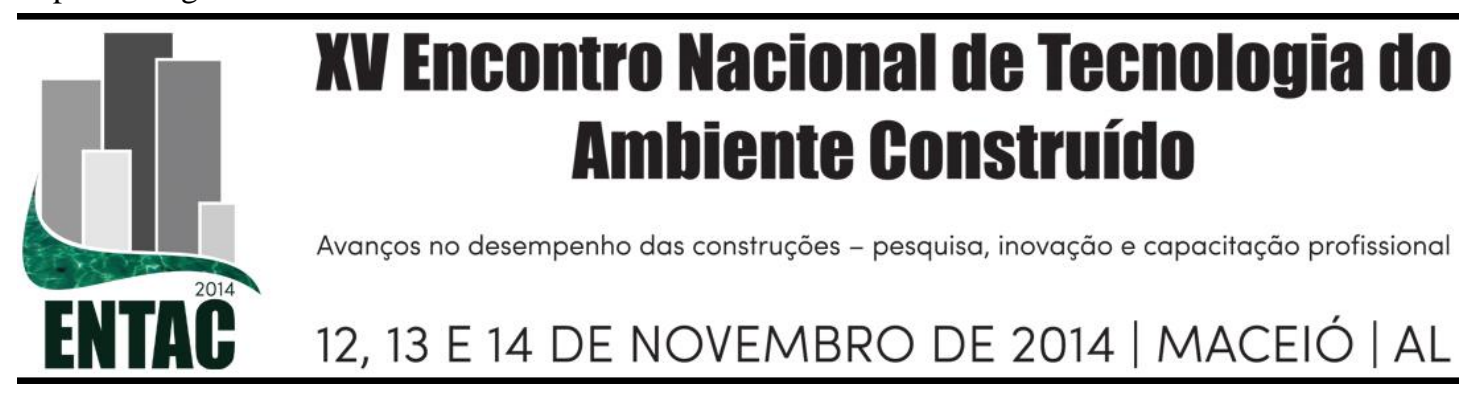

\title{
INFLUÊNCIA DA ABSORTÂNCIA SOLAR NO DESEMPENHO TÉRMICO DE HABITAÇÕES POPULARES
}

\author{
SCHAEFER, Aline (1); SILVA, Arthur Santos (2); ALMEIDA, Laiane S. Silva (3); \\ BALVEDI, Bruna (4); GHISI, Enedir (5) \\ Laboratório de Eficiência Energética em Edificações, Departamento de Engenharia Civil, Universidade \\ Federal de Santa Catarina, Brasil \\ (1) ali_ufsc@yahoo.com; (2) arthurssilva07@gmail.com; (3) brunabalvedi@live.com; (4) \\ lai_almeida@hotmail.com; (5) enedir@labeee.ufsc.br
}

\begin{abstract}
RESUMO
O desempenho térmico de edificações está fortemente relacionado com as características do seu envelope, dentre as quais cita-se a absortância solar. Relacionada com a cor da edificação, essa característica pode ser facilmente alterada, podendo promover melhoras no seu desempenho térmico a um baixo custo. Sob esse contexto, o objetivo deste estudo foi medir os valores de absortância solar de fachadas em habitações de interesse social da região de Florianópolis-SC e verificar sua influência no desempenho térmico destas edificações. Foram levantadas as refletâncias das fachadas de 101 habitações, com auxílio do espectrômetro portátil ALTA II. A partir dos dados de refletância medidos, calculou-se a absortância, indicador para simulação. Dois casos, um com menor área de fachada (modelo 1) e outro com maior (modelo 2), foram selecionados na amostra e submetidos à simulação computacional com o programa EnergyPlus, variandose parametricamente as absortâncias conforme levantadas em campo. Foram calculados os graus-hora de resfriamento e aquecimento a partir da temperatura operativa horária de cada ambiente, por meio da simulação. Os resultados dos levantamentos mostraram uma predominância dos casos compreendidos entre as faixas 0,1 e 0,2 , sendo que em 40 habitações obtiveram absortâncias baixas, abaixo de 0,3. Nas medições, os tons de cinza, madeira natural e salmão foram os que apresentaram as menores diferenças entre si (até 0,25 de diferença), enquanto os tons verde e azul apresentaram as maiores (até 0,60 de diferença). Com os resultados das simulações observou-se uma variação nos graus-hora de resfriamento maior no modelo 1 , de até $2510^{\circ} \mathrm{Ch}$. No aquecimento, a maior variação também foi no modelo 1, até $1980{ }^{\circ} \mathrm{Ch}$. Esses valores evidenciam a influência da absortância no desempenho térmico, o que possibilita fornecer subsídios para o desenvolvimento de políticas públicas voltadas à esse tipo de habitação que promovam melhor desempenho de forma prática e a baixo custo.
\end{abstract}

Palavras-chave: Habitação de interesse social, desempenho térmico, absortância solar.

\begin{abstract}
The building thermal performance is strongly related to the features of its envelope, among which is the solar absorptance. This feature, which is related to the colour of the building, can be easily modified, improving the thermal performance of buildings at a low cost. In this context, the aim of this study was to survey the solar absorptance of facades in social housing located in Florianópolis and verify its influence on the thermal performance of these buildings. Thus, the reflectance of 101 dwellings facades were surveyed, using the portable spectrometer ALTA II. The absorptances were calculated based on the measured reflectance data and used on the simulations. Two cases, one with a smaller facade area (model 1) and another with a larger (model 2), were selected in the sample and subjected to computer simulation, using EnergyPlus, by varying parametrically the absorptance on the values collected in the field. The degree-hour for cooling and heating were calculated with the hourly operative temperature values of each room obtained by the simulation. The results of the data collected showed a predominance of cases ranging between 0.1 and 0.2, and that the absorptance of 40 houses were below 0.3. Moreover, data revealed that the tones of grey, natural wood and salmon were the ones with the smallest deviations (up to 0.25
\end{abstract}


difference), while the green and blue tones had the largest (up to 0.60 difference). In addition, the simulations showed high variation of $2510^{\circ} \mathrm{Ch}$ on model 1 on cooling. On heating, the high variation was also obtained on model 1, with $1980{ }^{\circ} \mathrm{Ch}$. These values show the influence of absorptance in thermal performance of these dwellings, enabling the development of public policies aimed at social housing that promote better performance at a practical and low cost.

Keywords: Social Housing, thermal performance, solar absorptance.

\section{INTRODUÇÃO}

As edificações estão entre os maiores contribuintes para os impactos ao meio ambiente (UNEP, 2011), sendo seu gasto energético estimado em $40 \%$ em relação ao total global, dos quais apenas o setor residencial representa $30 \%$ do consumo de energia (IEA, 2012). No Brasil, as edificações são responsáveis por $47 \%$ do consumo de energia elétrica, sendo 23,6\% atribuídos ao setor residencial (EPE, 2013).

O consumo de energia nas edificações depende de muitos fatores. No caso do setor residencial, o consumo de energia está fortemente associado ao uso de condicionadores de ar (MCNEIL; LETSCHERT, 2010; FRACASTORO; SERRAINO, 2011; YU et al., 2011), o qual reflete no comportamento térmico da edificação. O desempenho térmico de um edifício é altamente impactado pelas características da envoltória devido à carga térmica gerada a partir de sua composição.

Muitos estudos mostram a influência da absortância no desempenho térmico de edificações (eg. SUEHRCKE; PETERSON; SELBY, 2008; HERNÁNDEZ-PÉREZ et al., 2014). Segundo a NBR 15220-1 (ABNT, 2005), a absortância pode ser definida como a razão entre a taxa de radiação solar incidente e a taxa de radiação solar absorvida por uma superfície. A relação deste parâmetro com o desempenho térmico da edificação está associada à quantidade de energia transformada em calor com a incidência de radiação na sua superfície. O calor produzido é transmitido para dentro da edificação e influencia na alteração das temperaturas internas (DORNELLES, 2008).

Um estudo que relacionou absortância e desempenho térmico foi o desenvolvido por Dornelles et al. (2010), que discute a relevância e abordagem da absortância no regulamento energético de edifícios brasileiros. Os autores realizaram estudos alterando os valores de absortância, obtendo como produto final a classificação do nível de eficiência da envoltória. Os resultados mostraram que a o nível de eficiência dos modelos é muito sensível às variações na absortância e sugere que sejam realizadas maiores reflexões sobre o tema.

Relacionada com a cor da edificação, além do potencial para redução do consumo de energia com sistemas de resfriamento da edificação, esta característica pode ser facilmente alterada nas edificações, podendo promover melhoras no seu desempenho térmico sem grandes investimentos financeiros. Sob esse contexto, é possível desenvolver políticas públicas voltadas às habitações de interesse social que promovam melhor desempenho de forma prática e a baixo custo.

Sob esse contexto, o objetivo deste estudo foi medir valores de absortância solar de fachadas em habitações de interesse social da região de Florianópolis-SC e verificar sua influência no desempenho térmico destas edificações por meio de simulação computacional. 


\section{MÉTODO}

O método aplicado a este estudo foi separado em duas etapas. A primeira etapa trata dos levantamentos dos dados em campo, enquanto na segunda foram realizadas simulações computacionais.

\subsection{Levantamento dos dados em campo}

O levantamento foi realizado em 101 habitações populares localizadas na Grande Florianópolis, no estado de Santa Catarina. Utilizou-se o espectrômetro ALTA II (Vernier Software \& Technology), instrumento utilizado para medição da refletância solar (Figura 1). Mediu-se a refletância das superfícies externas das fachadas das habitações.

Figura 1: Espectrômetro ALTA II

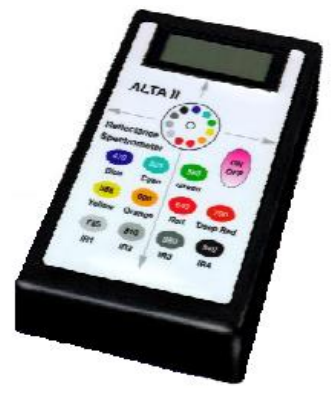

O procedimento de medição consiste em obter as refletâncias para cada comprimento de onda do espectro eletromagnético visível e infravermelho (referente a onze faixas de comprimento de onda). Como ele não mede o valor absoluto da refletância, este deve ser calculado utilizando-se como base uma amostra de referência. No caso desta pesquisa, a amostra de referência adotada foi uma folha de papel branco comum Ripax, de $75 \mathrm{~g} / \mathrm{m}^{2}$.

Na parte frontal do equipamento há onze botões correspondentes a cada comprimento de onda. Quando pressionados, o equipamento emite uma voltagem através de lâmpadas localizadas na parte posterior. Essa voltagem atinge a superfície em estudo e uma parte é refletida. A quantidade de energia refletida é percebida por um sensor e o valor correspondente é informado no visor. Para o cálculo da refletância, foi anotado o valor obtido em cada comprimento de onda, para a amostra de referência e para a amostra em estudo. Conforme orientações do fabricante, foram feitas três medições para cada caso e adotou-se a média aritmética dos dados das três medições.

A determinação da refletância adotada para cada faixa de cor foi calculada por meio da Equação 1.

$$
\rho_{\text {cor }}=\frac{\rho_{\text {branco }} \cdot \mathrm{V} \text { cor }}{(\mathrm{V} \text { branco })}
$$

onde, $\rho_{\text {cor }} \quad=$ refletância da amostra $(\%)$;

Pbranco = refletância do papel Ripax $(89,2 \%)$;

$\mathrm{V}_{\text {cor }} \quad=$ valor obtido na medição da amostra com o espectrômetro;

$\mathrm{V}_{\text {branco }}=$ valor obtido na medição do papel Ripax com o espectrômetro.

O valor de $\rho$ branco é um valor padronizado para cada folha, obtido a partir de análises com um espectrômetro. Os valores de referência utilizados nesta pesquisa estão apresentados na Tabela 1.

A refletância final da amostra é dada pela média aritmética das refletâncias de todas as onze cores. A partir dos dados de refletância medidos, obteve-se a absortância, que é o parâmetro usado nas simulações. A Equação 2 mostra o cálculo para se obter a absortância dada determinada refletância. 


$$
\alpha=100-\rho
$$

onde, $\rho \quad=$ refletância obtida $(\%)$;

$\alpha=$ absortância da $\operatorname{amostra}(\%)$.

Tabela 1: Valores de referência da refletância do papel Ripax por faixa de cor.

\begin{tabular}{|c|c|c|c|c|c|c|c|c|c|c|c|}
\hline Cor & $\begin{array}{c}\text { Blue } \\
470\end{array}$ & $\begin{array}{c}\text { Cyan } \\
525\end{array}$ & $\begin{array}{c}\text { Gree } \\
\mathrm{n} \\
560 \\
\end{array}$ & $\begin{array}{c}\text { Yello } \\
\text { W } \\
585 \\
\end{array}$ & $\begin{array}{c}\text { Orang } \\
\mathrm{e} \\
600 \\
\end{array}$ & $\begin{array}{l}\text { Red } \\
645\end{array}$ & $\begin{array}{c}\text { Deep } \\
\text { Red } \\
700 \\
\end{array}$ & $\begin{array}{l}\text { IR } 1 \\
735\end{array}$ & $\begin{array}{l}\text { IR } 2 \\
810\end{array}$ & $\begin{array}{c}\text { IR } 3 \\
880\end{array}$ & $\begin{array}{c}\text { IR } 4 \\
940\end{array}$ \\
\hline $\begin{array}{l}\text { Refletânci } \\
\text { a solar de } \\
\text { referência }\end{array}$ & $\begin{array}{c}0,87 \\
8\end{array}$ & $\begin{array}{c}0,84 \\
2\end{array}$ & 0,807 & 0,798 & 0,797 & $\begin{array}{c}0,87 \\
7\end{array}$ & $\begin{array}{c}0,95 \\
1\end{array}$ & $\begin{array}{c}0,96 \\
6\end{array}$ & $\begin{array}{c}0,96 \\
8\end{array}$ & $\begin{array}{c}0,97 \\
3\end{array}$ & $\begin{array}{c}0,95 \\
8\end{array}$ \\
\hline
\end{tabular}

Fonte: Dornelles et al. (2008).

\subsection{Simulação computacional}

Com os dados de absortância obtidos na etapa anterior foram realizadas simulações computacionais com o programa EnergyPlus versão 8.1 a fim de verificar a influência da absortância no desempenho térmico de edificações.

Duas habitações, uma com menor área de fachada (modelo 1) e outra com maior (modelo 2), foram selecionados da amostra pesquisada como modelos base para as simulações. As características geométricas de cada modelo foram modeladas com auxílio do Plug-in Open Studio, no programa Google Sketch Up. As Tabelas 2 e 3 apresentam áreas dos ambientes, cobertura e parede dos modelos computacionais, juntamente com as plantas baixas dos modelos 1 e 2 , respectivamente.

O clima de Florianópolis foi representado nas simulações com o arquivo climático do ano de referência, com extensão epw, disponibilizado no sítio eletrônico do LabEEE (<www.labeee.ufsc.br >). As trocas de calor entre o piso e o solo foram calculadas com o programa Slab, vinculado ao Energyplus. As trocas de ar entre a edificação e o meio foram configuradas com o objeto Airflownetwork.

As cargas internas e os materiais e sistemas construtivos foram configurados conforme levantado em campo, iguais para os dois casos. Para o modelo 1, considerou-se dois ocupantes na casa, e consumo de energia igual a $52 \mathrm{kWh} / \mathrm{mês}$, descontando-se o chuveiro elétrico. Para o modelo 2, considerou-se 6 ocupantes na casa, e consumo de energia igual a $41,5 \mathrm{kWh} / \mathrm{mês}$. Esse consumo de energia é distribuído entre equipamentos e iluminação, e gera carga interna que afeta o desempenho térmico, bem como o número de ocupantes e cada horário do dia. O sistema construtivo é de alvenaria de tijolos cerâmicos e cobertura de telha cerâmica e forro de madeira.

Foram realizadas simulações paramétricas com os dois modelos, para o ano todo, variando-se as absortâncias conforme as que foram levantadas em campo. Os dados de temperatura operativa dos ambientes de longa permanência, obtidos através das simulações, foram tratados com a Equação 3, a fim de se obter o valor de graus-hora de resfriamento, e com a Equação 4, para o valor de graus-hora de aquecimento. Foi calculado um único indicador para os graus-hora, denominado "graus-hora total", representando a soma do graus-hora de resfriamento e aquecimento de cada ambiente.

$$
G H_{r}=\sum\left(T_{o}-26^{\circ} C\right)
$$




$$
G H_{a}=\sum\left(18^{\circ} \mathrm{C}-T_{o}\right)
$$

onde, $\mathrm{GH}_{r} \quad$ = indicador de graus-hora para resfriamento;

$\mathrm{GH}_{a} \quad=$ indicador de graus-hora para aquecimento;

$T_{o} \quad=$ temperatura operativa $\left({ }^{\circ} \mathrm{C}\right)$.

Tabela 2: Planta baixa, representação do Open Studio e informações de áreas do modelo 1.

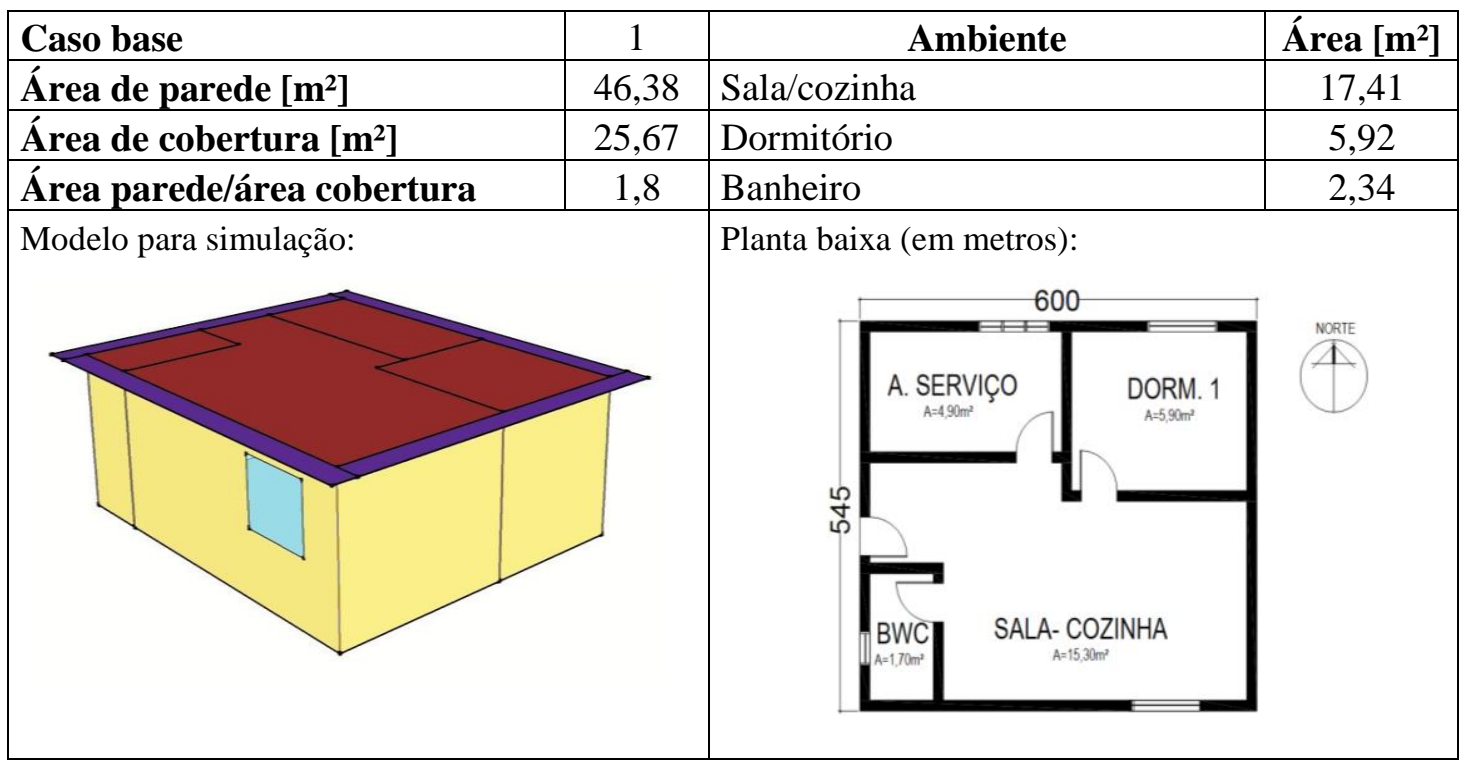

Tabela 3: Planta baixa, representação do Open Studio e informações de áreas do modelo 2.

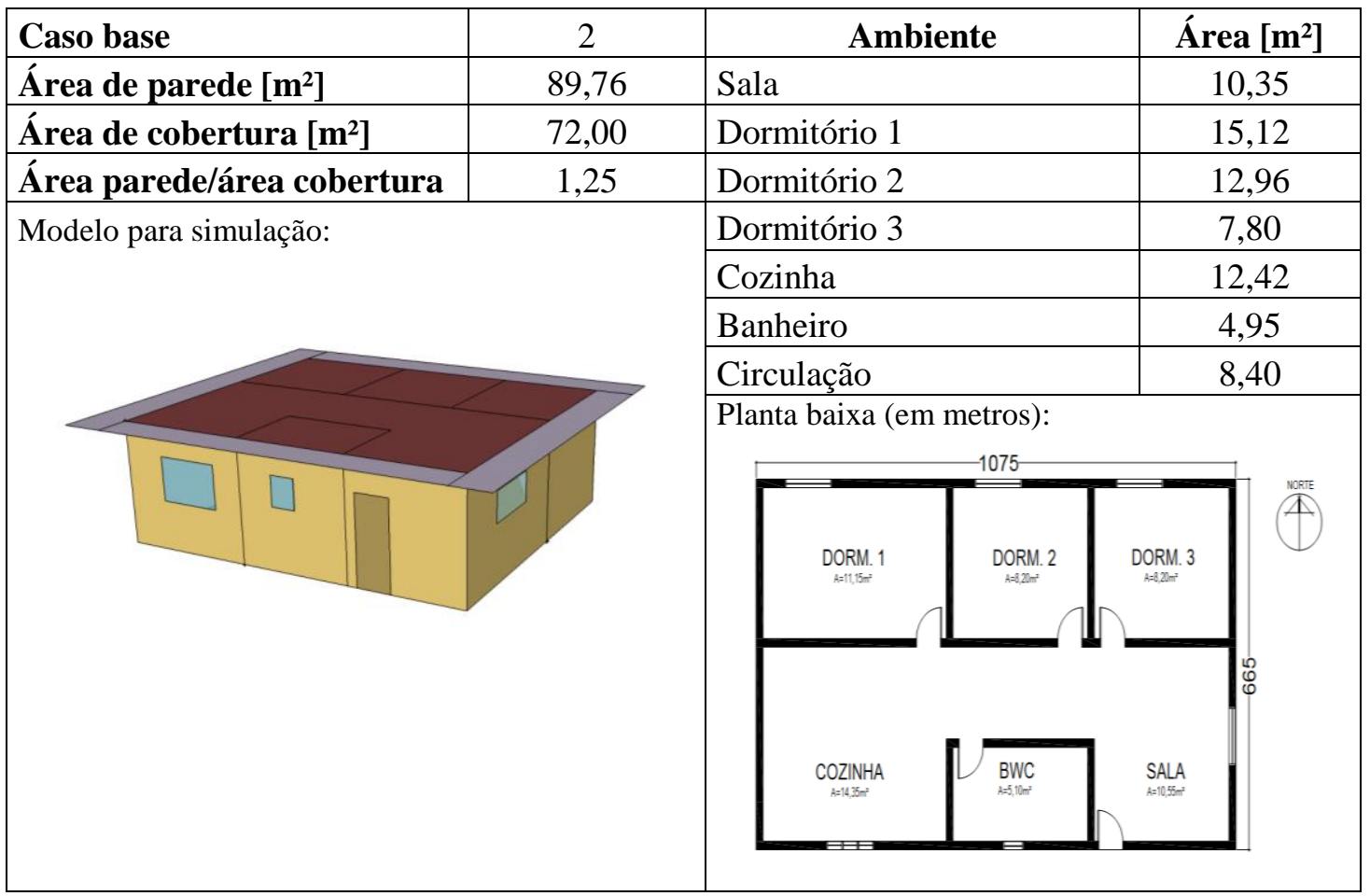




\section{RESULTADOS}

\subsection{Levantamento dos dados em campo}

A partir dos levantamentos, foram encontradas onze cores diferentes, com as absortâncias variando de 0,07 (cor branca) até 0,87 (reboco sem pintura). Dentre as cores encontradas, a Figura 2 apresenta a quantidade de habitações que apresentaram cada cor das fachadas, sendo que 25 apresentaram cor branca e 21, cor amarela.

Os resultados mostraram uma predominância na utilização de cores mais claras na fachada, nos casos compreendidos entre as faixas 0,1 e 0,2 (21 habitações), sendo que em 40 habitações as absortâncias ficaram abaixo de 0,3.

\section{Figura 2: Cores encontradas na pintura externa}

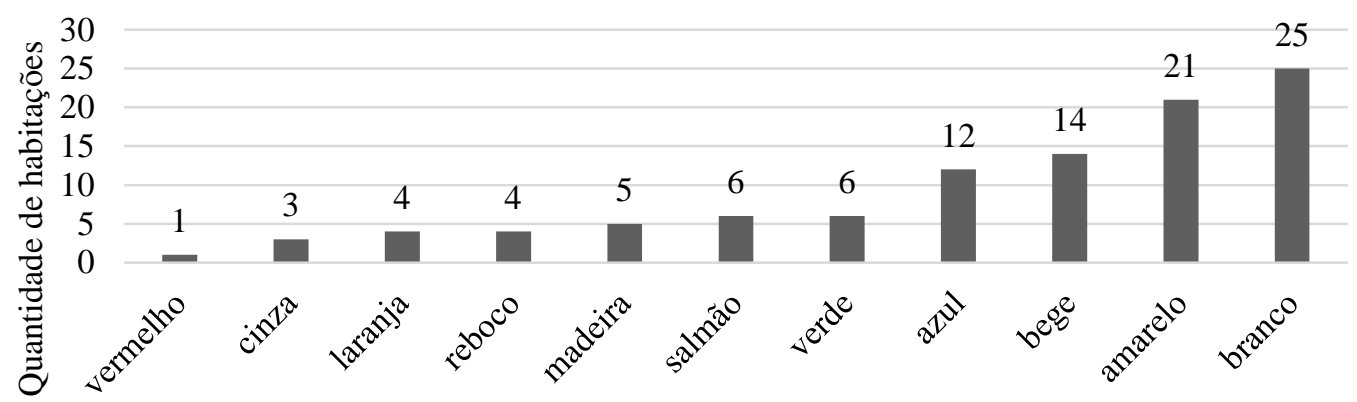

Cores encontradas

A Figura 3 apresenta os diferentes valores de absortância para cada cor. As cores cinza, madeira natural e salmão foram os que apresentaram as menores variações de valor (menos de 0,25 entre medições). A cor cinza resultou em absortância média de 0,47.

As absortâncias obtidas para madeira natural variaram de 0,51 a 0,71 , e para o salmão de 0,13 a 0,38 . As cores azul e verde apresentaram as maiores variações valor, chegando até 0,57 de diferença entre a menor medida e a maior para a cor verde, e 0,60 para a cor azul. De fato, estas duas cores apresentam uma vasta diferença de tonalidade, influenciando os resultados de absortância. A Figura 4 mostra a diferença de tonalidade para a cor azul, como exemplo.

Figura 3: Valores de absortância encontrados para cada cor
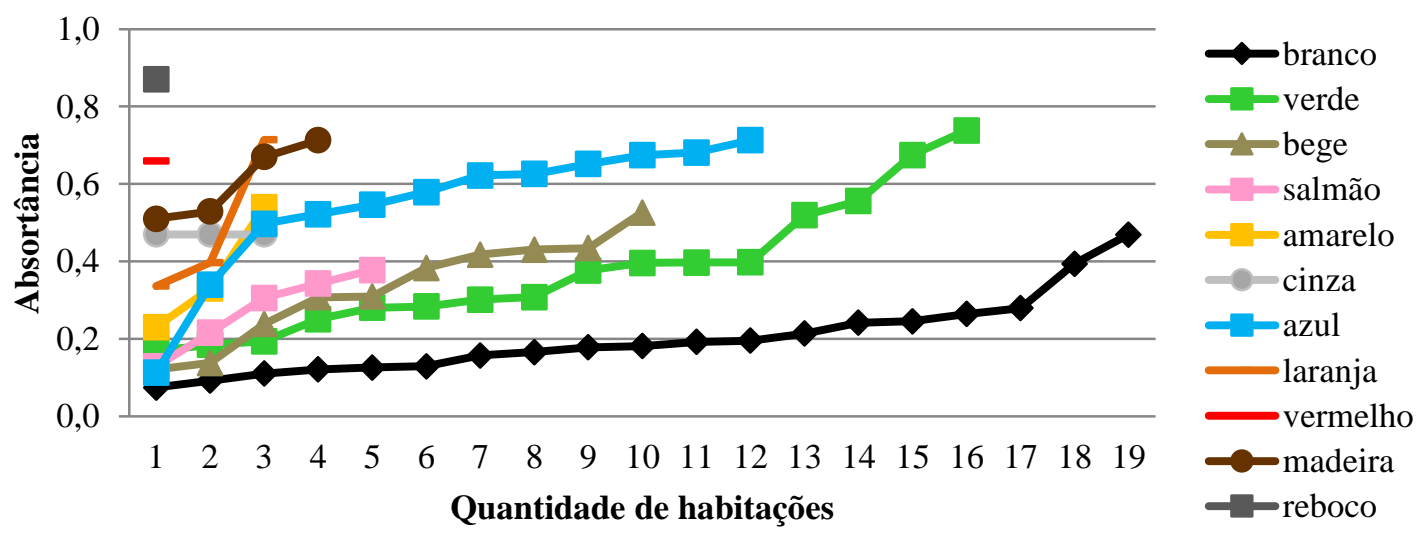
Figura 4: Variação das tonalidades de azul na amostra levantada
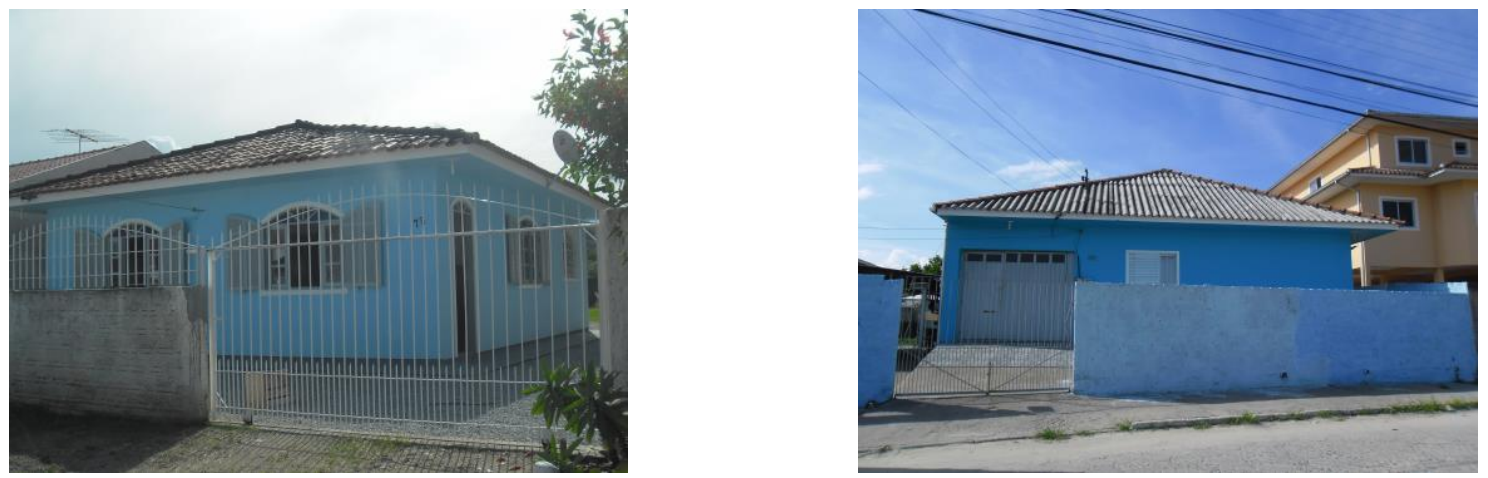

A Figura 5 apresenta a absortância média por cor, determinada pela média aritmética de todas as medidas de absortância para cada cor. O branco, como esperado, teve a menor absortância média $(0,20)$, enquanto as cores mais escuras, como o vermelho, a madeira natural e o reboco, as maiores $(0,61,0,66$ e 0,87 , respectivamente).

\section{Figura 5: Absortância média por cor}

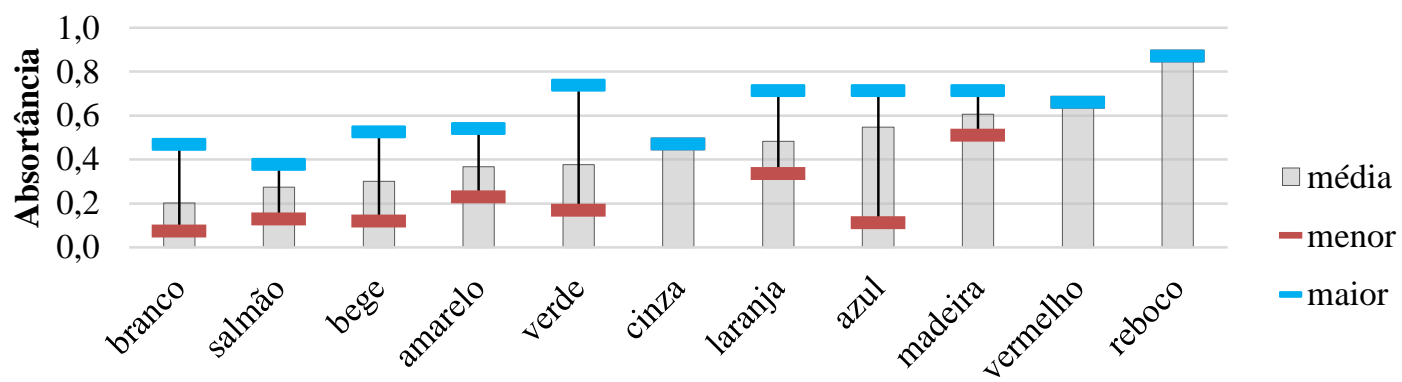

Cores encontradas nas fachadas da amostra

\subsection{Simulação computacional}

A Figura 6 mostra a variação dos valores de graus-hora de resfriamento, graus-hora de aquecimento e graus-hora total para os modelos 1, e a Figura 7 mostra o mesmo para o modelo 2, a partir da variação da absortância.

Com os resultados das simulações observou-se variação de 2038 graus-hora de aquecimento no quarto do modelo 1, e 690 graus-hora de resfriamento no quarto do modelo 1. No modelo 2 uma variação menor foi obtida, sendo que a máxima foi de 1091 graus-hora de resfriamento na sala e a menor foi de $519{ }^{\circ} \mathrm{Ch}$ no aquecimento na sala. Esses valores mostram a influência da absortância no desempenho térmico dessas habitações.

O aumento da absortância contribuiu para o aumento dos graus-hora de resfriamento, ao mesmo tempo que contribuiu para a diminuição dos graus-hora de aquecimento. Como resultado, quando considerados a soma dos graus-hora de resfriamento e de aquecimento, observa-se que a variação em relação ao aumento da absortância diminui. 
Figura 6: Valores de graus-hora dos ambientes para cada absortância simulada para o Modelo 1.
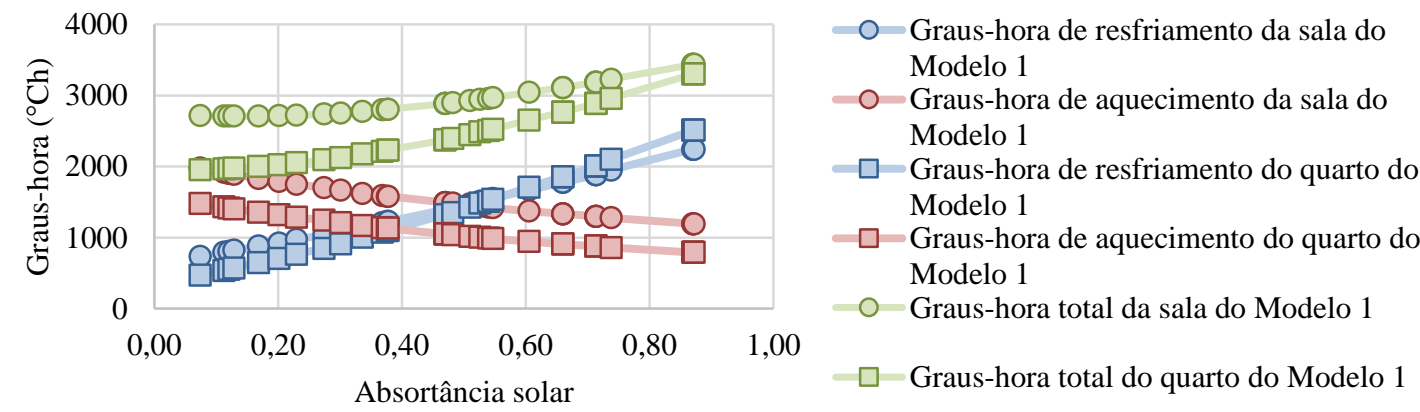

Figura 7: Valores de graus-hora dos ambientes para cada absortância simulada para o Modelo 2.
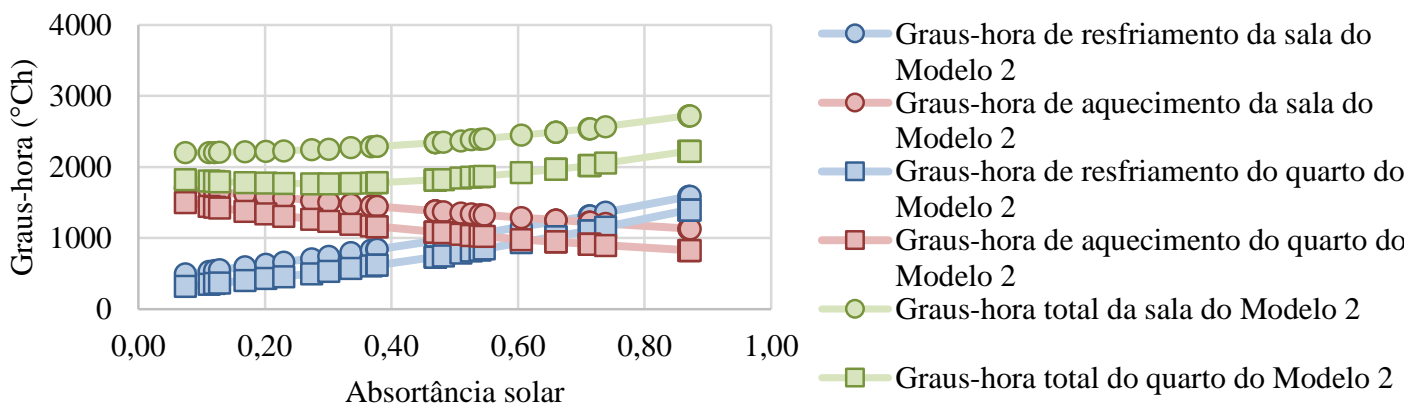

A Figura 8 mostra a variação do valor de graus-hora total de cada modelo e cada ambiente quando são adotados os valores de absortância mínimo, médio e máximo obtidos para cada cor. Observa-se que, em função das diferentes tonalidades, a variação de graus-hora pode assumir valores bem diferentes para uma mesma cor, como é o caso da coe "salmão", "azul" e "vermelho", os quais podem variar bastante o valor dos graus-hora em função da tonalidade.

Figura 8: Valores de graus-hora total por ambiente e por modelo, para absortância mínima, média e máxima por cor.

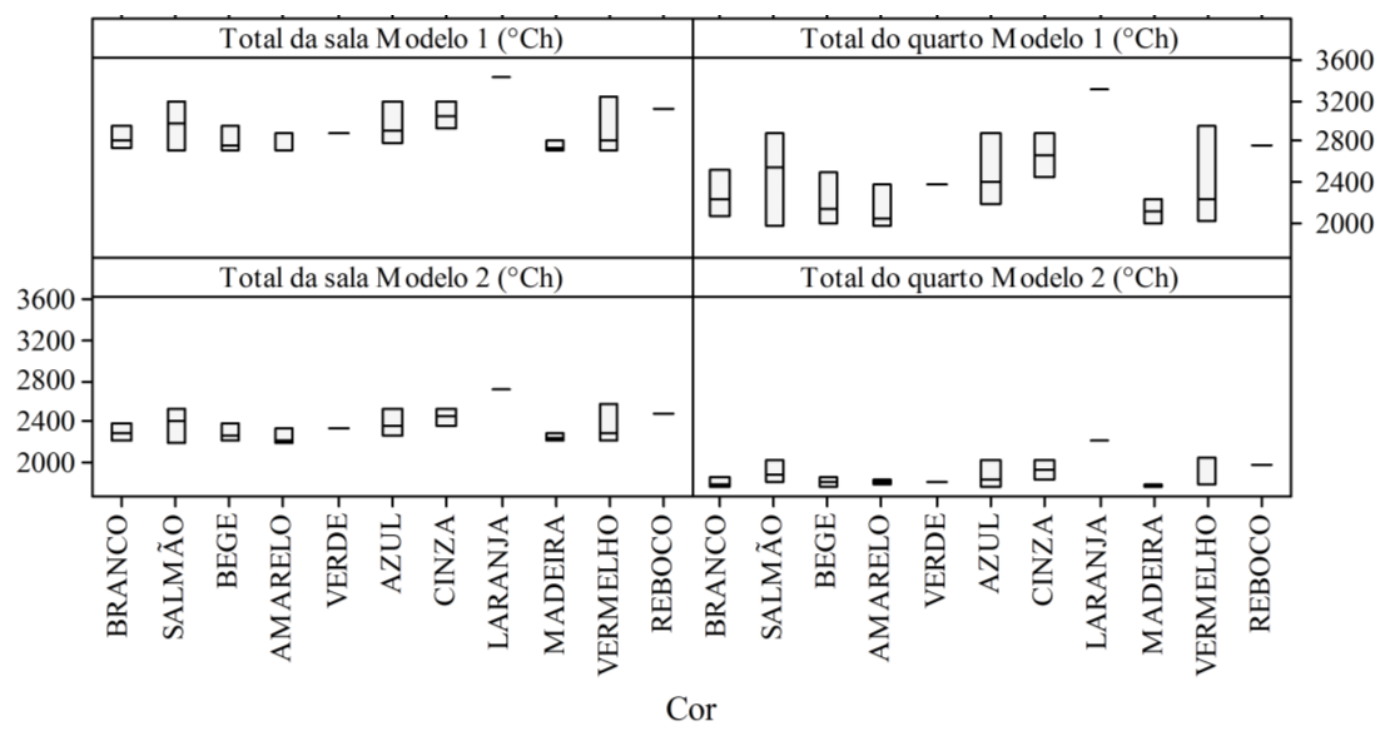




\section{CONCLUSÕES}

Neste estudo foram apresentadas as diferentes absortâncias encontradas em campo nas habitações populares de Florianópolis-SC e seu efeito sobre o desempenho térmico destas. Observou-se que há uma variedade moderada de cores, embora o uso de cores claras seja predominante. Observou-se também haver grande variação de tonalidades para algumas cores, como o azul e verde, com consequente grande variação nas absortâncias obtidas nestes casos.

Quanto às simulações, os resultados mostraram que a absortância de fato exerce grande influência no desempenho térmico de edificações, visto o aumento gradual do valor de graus-hora para cada aumento no valor da absortância, chegando a quadruplicar nos casos mais extremos.

Pode-se concluir a partir dos resultados das simulações que a absortância exerce maior influência nas situações de necessidade de resfriamento das edificações do que de aquecimento.

Com esse cenário, é possível desenvolver políticas públicas voltadas às habitações de interesse social que promovam melhor desempenho de forma prática e a baixo custo. Entretanto, é preciso estar atento ao fato de que grande parte das edificações já possui um valor baixo de absortância solar. Além disso, a variação da absortância, em função das diferentes tonalidades de uma mesma cor, mostra que selecionar a tinta pela cor não parece o processo mais adequado, da mesma forma que para um leigo comprar a tinta pelo valor da absortância pode ser um procedimento pouco prático. Dessa forma, caso sejam desenvolvidas políticas públicas envolvendo absortâncias se faz necessário em conjunto um estudo maior quanto a forma que será realizada a sua comercialização.

\section{AGRADECIMENTOS}

Os autores agradecem à Financiadora de Estudos e Projetos (Finep) que possibilitou a realização desse trabalho.

\section{REFERÊNCIAS}

ASSOCIAÇÃO BRASILEIRA DE NORMAS TÉCNICAS. NBR 15220-1: desempenho térmico de edificações - Parte 1 Definições, símbolos e Unidades. Rio de Janeiro. ABNT, 2005.

BEN Balanço Energético Nacional. Ministério de Minas e Energia. Disponível em: <http://www.mme.gov.br/mme>. Acesso em 20/10/2012.

DORNELLES, K. A. Absortância solar de superfícies opacas: métodos de determinação e base de dados para tintas látex acrílica e PVA. 2008. 160p. Tese (Doutorado) - Faculdade de Engenharia Civil, Arquitetura e Urbanismo, Universidade Estadual de Campinas. Campinas, 2008.

DORNELLES, K. A.; SANTOS, I. G.; SOUZA, R. V. Absortância solar de superfícies e o regulamento brasileiro para eficiência energética de edifícios. In: Encontro Nacional de Tecnologia do Ambiente Construído, 2010. Anais... Gramado, 2010.

EPE. Empresa de Pesquisa Energética. Balanço Energético Nacional 2013: Ano base 2012. Empresa de Pesquisa Energética - Ministério de Minas e Energia - MME. Rio de Janeiro, 2012a. 
FRACASTORO, G. V.; SERRAINO, M. A methodology for assessing the energy performance of large scale building stocks and possible applications. Energy and Buildings, v. 43, n. 4, p. 844-852, 2011.

HERNÁNDEZ-PÉREZ, I.; ÁLVAREZ, G.; XAMÁN, J.; ZAVALA-GUILLÉN, I.; ARCE, J.; SIMÁ, E. Thermal performance of reflective materials applied to exterior building components-A review. Energy and Buildings, v. 80, September 2014, p. 81$105,2014$.

IEA. International Energy Agency. Key World Energy Statistics. [s.l: s.n.]. Disponível em: <http://www.iea.org/publications/freepublications/publication/kwes.pdf $>$. Acesso em 20/10/2012.

MCNEIL, M. A.; LETSCHERT, V. E. Modeling diffusion of electrical appliances in the residential sector. Energy and Buildings, v. 42, n. 6, p. 783-790, 2010.

SUEHRCKE, H.; PETERSON, E.L.; SELBY, N. Effect of roof solar reflectance on the building heat gain in a hot climate. Energy and Buildings, v. 40, n. 12, p. 2224-2235, 2008.

UNEP. Buildings: Investing in energy and resource efficiency. In: UNEP (Ed.). Towards a Green Economy: Pathways to Sustainable Development and Poverty Eradication. 02.11.2011. ed. [s.1.], p. 330-373. United Nations Environment Programme, 2011

YUA, Z; FUNGB, B.C.M.; HAGHIGHATA, F.; YOSHINOC, H.; MOROFSKYD, E. A systematic procedure to study the influence of occupant behavior on building energy consumption. Energy and Buildings, v. 43, n. 6, p. 1409-1417, 2011. 